\title{
Grid Connected Distributed Generation System with High Voltage Gain Cascaded DC-DC Converter Fed Asymmetric Multilevel Inverter Topology
}

\author{
S. Nagaraja Rao ${ }^{1}$, D. V. Ashok Kumar ${ }^{2}$, Ch. Sai Babu ${ }^{3}$ \\ ${ }^{1,3}$ Department of Electrical and Electronics Engineering, JNT University, India \\ ${ }^{2}$ Department of Electrical and Electronics Engineering, RGMCET, India
}

\begin{tabular}{l} 
Article Info \\
\hline Article history: \\
Received Nov 19, 2017 \\
Revised Feb 7, 2018 \\
Accepted Jul 31, 2018 \\
\hline Keyword: \\
Asymmetric multilevel inverter \\
Distributed generation \\
Grid integration \\
High-gain DC-DC converter
\end{tabular}

High-gain DC-DC converter

\begin{abstract}
The paper presents distributed generation (DG) system in grid connected mode of operation with asymmetric multi-level inverter (AMLI) topology. Cascaded type DC-DC converter is employed to feed proposed AMLI topology. The DG output voltage (generally low voltage) is stepped up to the required level of voltage using high-gain DC-DC converter. Proposed AMLI topology consists of capacitors at the primary side. The output of high-gain DC-DC converter is fed to split voltage balance single-input multi-output (SIMO) circuit to maintain voltage balance across capacitors of AMLI topology. Cascaded DC-DC converters (both high-gain converter and SIMO circuit) are operated in closed-loop mode. The proposed AMLI feeds active power to grid converting DC type of power generated from DG to AC type to feed the grid. PWM pattern to trigger power switches of AMLI is also presented. The inverting circuit of MLI topology is controlled using simplified $\mathrm{I}_{\mathrm{d}}-\mathrm{I}_{\mathrm{q}}$ control strategy in this paper. With the proposed control theory, the active power fed to grid from DG is controlled and power factor is maintained at unity. The proposed system of DG integration to grid through cascaded DC-DC converters and AMLI structure is validated from fixed active power to grid from DG condition. The proposed system is developed and results are obtained using MATLAB/SIMULINK software.
\end{abstract}

Copyright @ 2018 Institute of Advanced Engineering and Science. All rights reserved.

\section{Corresponding Author:}

S. Nagaraja Rao,

Department of Electrical and Electronics Engineering,

Jawaharlal Nehru Technological University,

Kakinada, Andhra Pradesh, 533003, India.

Email: nagarajraomtech@gmail.com

\section{INTRODUCTION}

Renewables have accounted for more than half of all capacity additions in the power sector in recent and past ages. The power generation using the renewable sources is called as distributed generation (DG). Renewable energy (RE) technologies for electricity generation can be grouped into dispatchable renewables (e.g. hydro, geothermal and biomass power), which are basically ready for production upon demand, and non-dispatchable or variable renewables (e.g. wind and solar), whose electricity production depends upon meteorological conditions and/or the time of the day. The paper deals with electrical power generation using non-dispatchable renewable power technologies-primarily solar power-into the power grids. The typical modular size of variable renewable technologies is well suited to distributed power generation systems [1]-[2] in which a number of small power plants are connected to the distribution grid and produce electricity close to the demand site.

Generally DG [3]-[4] (solar, in this context) generates DC power of low voltage. This DG produced low voltage is not sufficient to drive any of the electrical system and thus the low voltage from DG is 
increased to a level such that system voltage requirements are met. To increase the DC level of voltage, a DC-DC converter [5]-[6] is employed. A DC-to-DC converter is an electronic circuit or electromechanical device that converts a source of direct current (DC) from one voltage level to another. It is a type of electric power converter. Power levels range from very low (small batteries) to very high (high-voltage power transmission). DC to DC converters which are developed to maximize the energy harvest for photovoltaic systems and for wind turbines are called power optimizers. DC to DC converters in electronic circuits use switching technology. Switched mode DC-DC converter converts the DC voltage level by storing the input energy temporarily and then releases that energy at different voltage output.

The storage is done either in magnetic field components like an inductor, transformers or electric field components like capacitors [7]-[8]. This conversion method can increase or decrease the voltage level. The efficiency of the converter has increased drastically due to the use of power FETs, which are able to switch more efficiently with lower switching losses at higher frequencies than power bipolar transistors and use less complex drive circuitry. DG can be operated in islanding mode or grid interfacing mode of operations. The integration of a significant share of variable renewables into power grids requires a substantial transformation of the existing networks. Grid integration scheme of DG [9]-[10] insists for for inverter circuit to invert the DC type of supply from DG (solar) to AC type.

An electrical power inverter is basically a circuit that converts a DC signal into an AC signal. The simplest topology that can be used for this conversion is the two-level inverter that consists of four switches. Each switch needs an anti-parallel diode, so there should be also four anti parallel diodes. Conventional twolevel inverter produces square-wave inverted output containing infinite harmonics which further insists for high sized filters to obtain sinusoidal output shape [11]. Conventional inverter imposes high stress on switches (increasing losses) which results in increased insulation density to withstand voltage stress which further increases the cost of the system due to high sized filters and insulation level. To eliminate the disadvtanges in conventional two-level inverters, multi-level inverters are developed. A multilevel inverter [12]-[13] is a power electronic system that synthesizes a sinusoidal voltage output from several DC sources.

The THD will be decreased by increasing the number of levels. It is obvious that an output voltage with low THD is desirable, but increasing the number of levels needs more hardware, also the control will be more complicated. It is a tradeoff between price, weight, complexity and a very good output voltage with lower THD. In this paper reduced switch MLI is introduced with single DC source for renewable energy application. The proper balancing of capacitor is required to achieve the desired output voltage level. The proposed topology can operate at both symmetric and asymmetric condition. The term 'asymmetric' indicates that the utilized DC sources are different in voltage magnitude. The main objective of asymmetric MLI is to generate a higher number of output voltage levels with the same number of component when compared to symmetric MLI [14].

In any grid connected applications, the main objective of the control strategy is to control active power injection with unity power factor control. The inverting circuit of MLI topology is controlled using simplified $I_{d}-I_{q}$ control strategy in this paper. The proposed control strategy takes active and reactive power reference signals and from this Id and Iq currents are calculated and fed to control structure. The proposed control theory is verified with fixed power reference. Proposed control strategy is similar to $I_{d}-I_{q}$ control theory of active power filters with some modifications since the theory is applied to grid connected application with the aim of active and reactive power control. In order to maintain the unity power factor, grid voltage is taken as reference and thus the frequency component of grid current is generated.

Grid connected distributed generation (DG) system with asymmetric multi-level inverter (AMLI) topology fed from cascaded DC-DC converters is shown in Figure 1. The paper presents grid connected distributed generation (DG) system with novel multi-level inverter (MLI) topology. DG output is fed to high gain DC-DC converter (boost) to increase the voltage level. Proposed MLI topology consists of capacitors at primary side. The output of high-gain DC-DC converter is fed to split voltage balance single-input multioutput (SIMO) circuit to maintain voltage balance across capacitors of AMLI topology. Cascaded DC-DC converters (both high-gain converter and SIMO circuit) are operated in closed-loop mode. The proposed AMLI feeds active power to grid converting DC type of power generated from DG to AC type to feed grid. PWM pattern to trigger power switches of AMLI is presented. The bridge circuit of AMLI topology is controlled using simplified Id-Iq control strategy in this paper. The proposed system of DG integration to grid through cascaded DC-DC converters and novel MLI structure is validated from fixed load and variable load conditions. The proposed system is developed and results are obtained using MATLAB/SIMULINK software. 


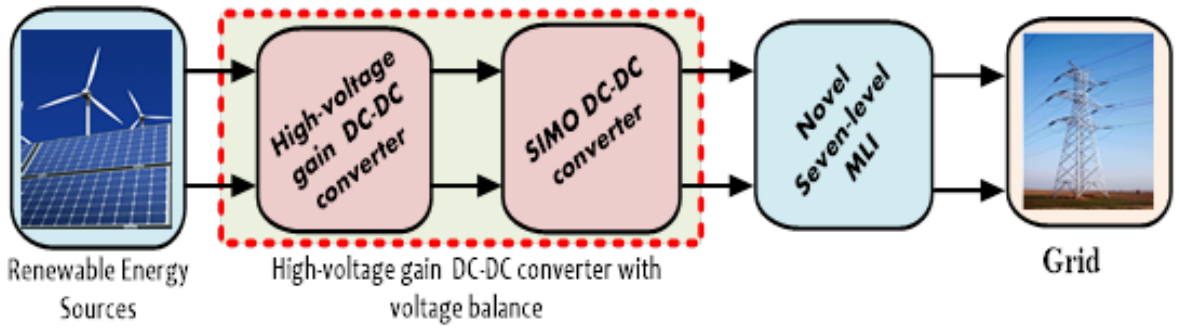

Figure 1. Block diagram of proposed system

\section{CASCADED DC-DC CONVERTERS}

\subsection{DC-DC Multilevel Boost Conveter}

The configuration of DC-DC three level boost converter is depicted in Figure 2. It consists of conventional boost converter, $(2 \mathrm{~N}-1)$ diodes and $(2 \mathrm{~N}-1)$ capacitors. The main advantages by using the proposed topology are it can be extended to $\mathrm{N}$-number of levels by adding only diodes and capacitors without modifying the main circuit, high voltage gain can be obtained without use of transformer and high duty cycle. The proposed converter consists of 3 stages which is operated at duty cycle of 0.5 . The operation of the three level boost converter is explained in [6].

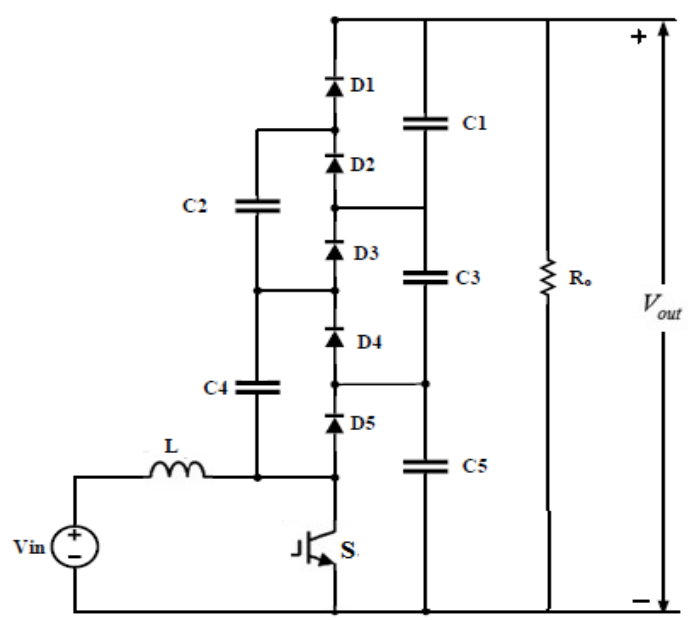

Figure 2. High-voltage Three level DC-DC boost converter

From basic principles, the voltage gain of the conventional boost converter is given by

$$
\text { Voltage gain, } \frac{\mathrm{V}_{\mathrm{o}}}{\mathrm{V}_{\mathrm{dc}}}=\frac{1}{1-\mathrm{D}}
$$

For MBC, the voltage gain is expressed as

$$
\frac{\mathrm{V}_{\mathrm{o}}}{\mathrm{V}_{\mathrm{dc}}}=\frac{\mathrm{N}}{1-\mathrm{D}}
$$

From (1) and (2), it is observed that the voltage gain can be controlled with duty cycle ' $\mathrm{D}$ ' in the PWM.

\subsection{Single-input Multi-output (SIMO) Converter}

The SIMO isolated DC-DC converter achieves or performs two major tasks-one is to boost the input DC voltage from high gain DC-DC converter to higher value of voltage as boost converter and the other to balance the voltage across capacitors in proposed MLI topology. As the name suggests of isolated DC-DC converter, DC-DC converter consists of transformer for isolation of input side to the output. The transformer is of multi winding transformer and gives three output ports. At the input, the transformer is supplied from a DC source. 
The main disadvantage of considering RES for electricity generation is that RES produces lowvoltage output which insists for boost operation of voltage using DC-DC converter. Two back-to-back DCDC converters are employed in this paper to feed power from DG to proposed MLI. DG output is fed to high gain DC-DC converter (boost) to increase the voltage level. Proposed MLI topology consists of capacitors at primary side. The output of high-gain DC-DC converter is fed to split voltage balance single-input multioutput (SIMO) circuit to maintain voltage balance across capacitors of MLI topology.

The circuit representation of single-input multi-output (SIMO) isolated DC-DC converter is shown in Figure 3. In this paper the output of high voltage gain DC-DC converter is supplied as input to the transformer primary. A switch MOSFET is connected to the transformer primary and the switching operation of switch decides the charging time of input primary coil of transformer. The secondary of the transformer consists of three output ports with single input port and hence the circuit is termed as single-input multioutput isolated DC-DC converter. Each output port of the DC-DC converter has a diode connected along with the capacitor at the output terminal of the port. Diode is placed to prevent reverse current flow from capacitor to windings of transformer.

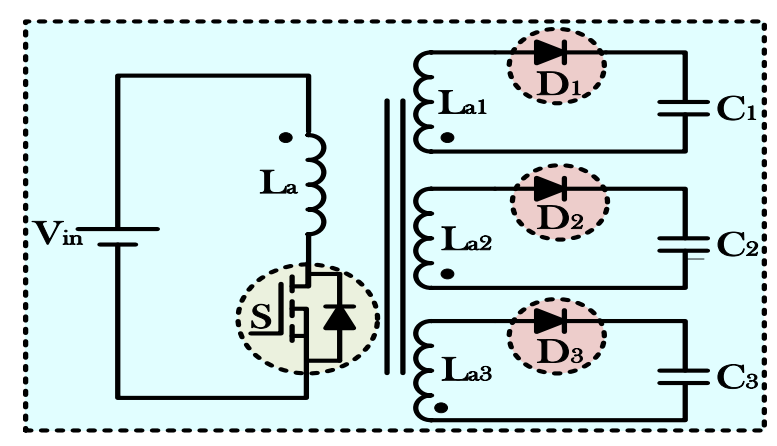

Figure 3. Single-input Multi-output (SIMO) converter with voltage balancing

The closed-loop control of single-input multi-output isolated DC-DC converter is shown in Figure 4. Conventional multi-output converters when operated in closed-loop mode of operation involves multiple PI controllers to reduce the error but this paper presents the use of only single PI controller to reduce the error in all three output ports of DC-DC converter. The voltage across each of the three output ports of single-input multi-output isolated DC-DC converter are measured across respective individual capacitors connected at the respective output port terminals of DC-DC converter.

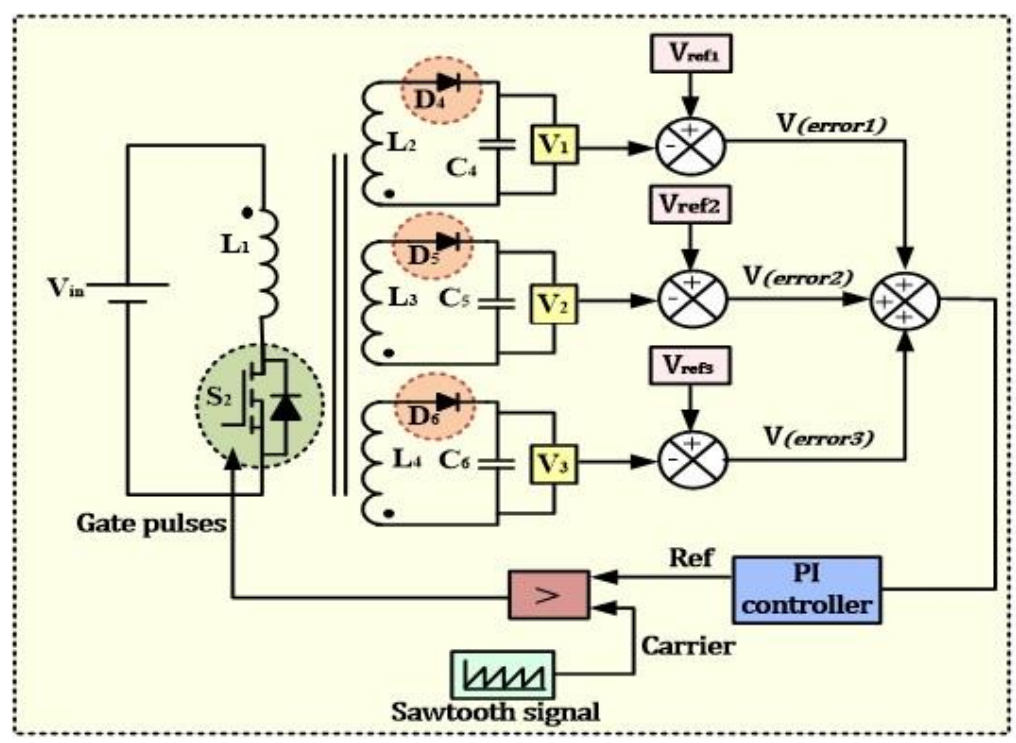

Figure 4. Closed-loop operation of Single-input Multi-output (SIMO) converter 
The actual measured output voltage across capacitor is measured and is compared with reference voltage yielding the error in each of the individual secondary sides. The process error in all the three voltages across capacitors is added and sent to a PI controller block. PI controller reduces the error and yields the reference signal. This reference signal is compared logically with carrier (saw-tooth) signal (when reference greater than carrier signal) which generates switching pulses to MOSFET. ON/OFF times of MOSFET reflects the charging time of primary coil of transformer and hence each of the output capacitors are charged to correct value of voltage. This phenomenon balances the voltage across capacitors of SC-MLI. Also, during the ON time of MOSFET, the primary coil of transformer is charged and boosts the input voltage and transfers the input voltage to the secondary side. This SIMO isolated DC-DC converter achieves or performs two major tasks - one is to boost the input DC voltage from high gain DC-DC converter to higher value of voltage as boost converter and the other to balance the voltage across capacitors in MLI topology.Complete phenomenon of renewable energy source fed DC-DC converters for high voltage-gain boosting and singleinput multi-output voltage balancing with their respective closed-loop operations is depicted in Figure 5.

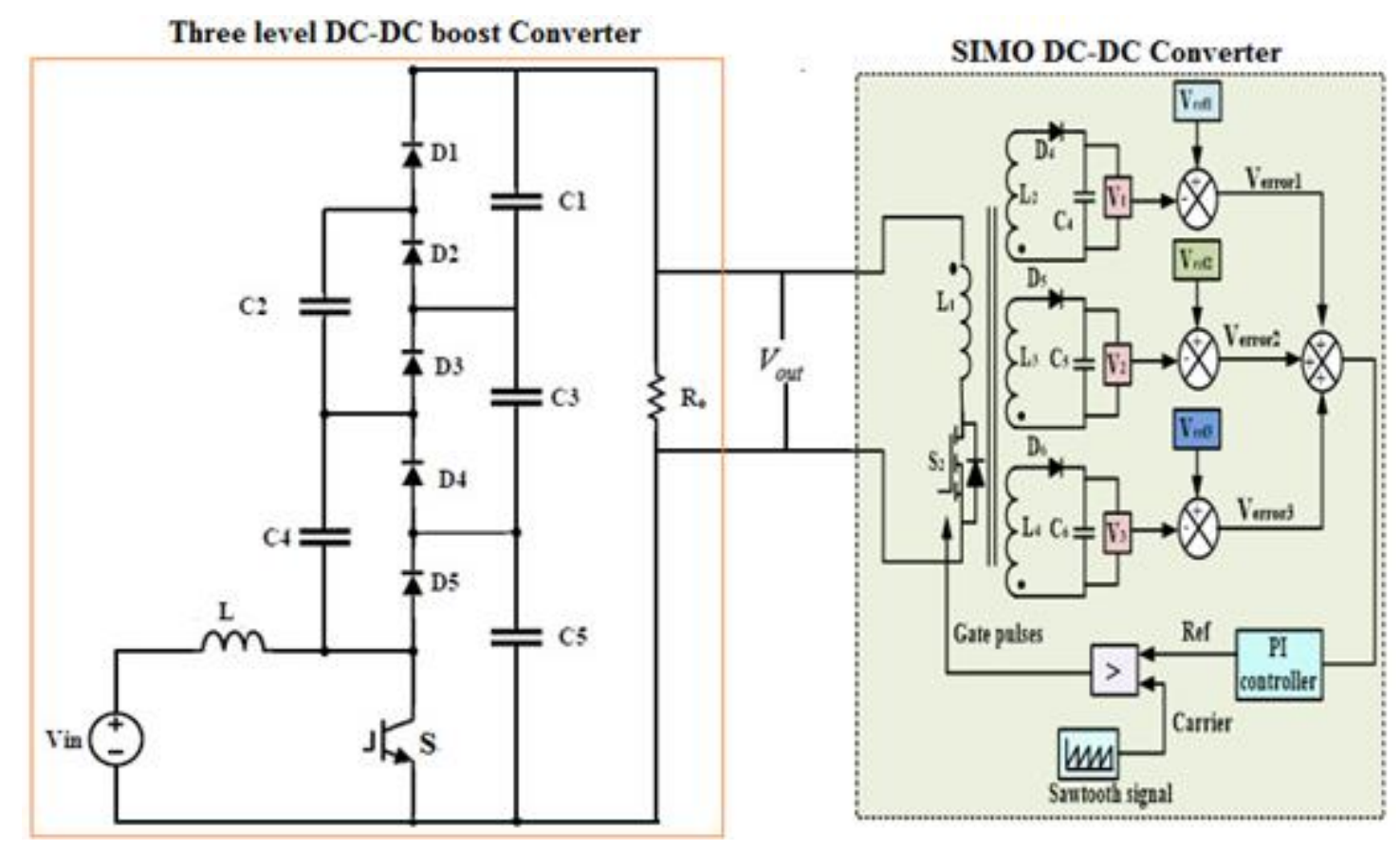

Figure 5. Complete phenomenon of renewable energy source fed DC-DC converters for high voltage-gain boosting and single-input multi-output voltage balancing with their respective closed-loop operations

\section{PROPOSED ASYMMETRIC MULTI-LEVEL INVERTER TOPOLOGY (AMLI)}

\subsection{Topology}

Figure 6 shows the proposed topology of single-phase AMLI to generate 15 levels. Three phase topology of 15-level proposed AMLI is formed by adding two similar phases as like in Figure 6. The proposed type of MLI is cascaded in model and produces stepped output to form 15-level output. The topology proposed consists of ten power switches in which six are used for switching operation and four are used for polarity generation in half-bridge topology. The switches $S_{a 1}$ to $S_{a 6}$ are used in cascaded structure and switches $S_{a 7}$ to $S_{a 10}$ are placed in half-bridge structure in one phase of proposed topology. Three DC sources are required to generate 15-level output and dc sources are formed by connecting a number of halfbridge cells in series with each cell having a voltage source controlled by two switches. The maximum output voltage is the sum of all the dc source voltages, and is given (3) and (4).

$$
\begin{aligned}
& \mathrm{V}_{0}, \max =\mathrm{V}_{1}+\mathrm{V}_{2}+\ldots \ldots . \mathrm{V}_{\mathrm{n}} \\
& \mathrm{V}_{0}, \max =\sum_{i=1}^{n} V_{n}
\end{aligned}
$$


Equations (3) and (4) illustrate the output level of the adder/subtraction circuit. Both the positive and negative levels are synthesized at load $\left(\mathrm{V}_{\mathrm{o}}\right)$ using the equations (5) and (6). At load $\left(\mathrm{V}_{\mathrm{o}}\right)$, the synthesized stepped output voltage level will be obtained as mentioned below:

$$
\begin{aligned}
& \mathrm{V}_{0}, \max =\sum_{\mathrm{i}=1}^{\mathrm{n}}+\mathrm{V}_{\mathrm{i}}, \text { If } \mathrm{S}_{1}, \mathrm{~S}_{4}=1 \\
& \mathrm{~V}_{0}, \max =\sum_{\mathrm{i}=1}^{\mathrm{n}}-\mathrm{V}_{\mathrm{i}}, \text { If } \mathrm{S}_{2}, \mathrm{~S}_{3}=1
\end{aligned}
$$

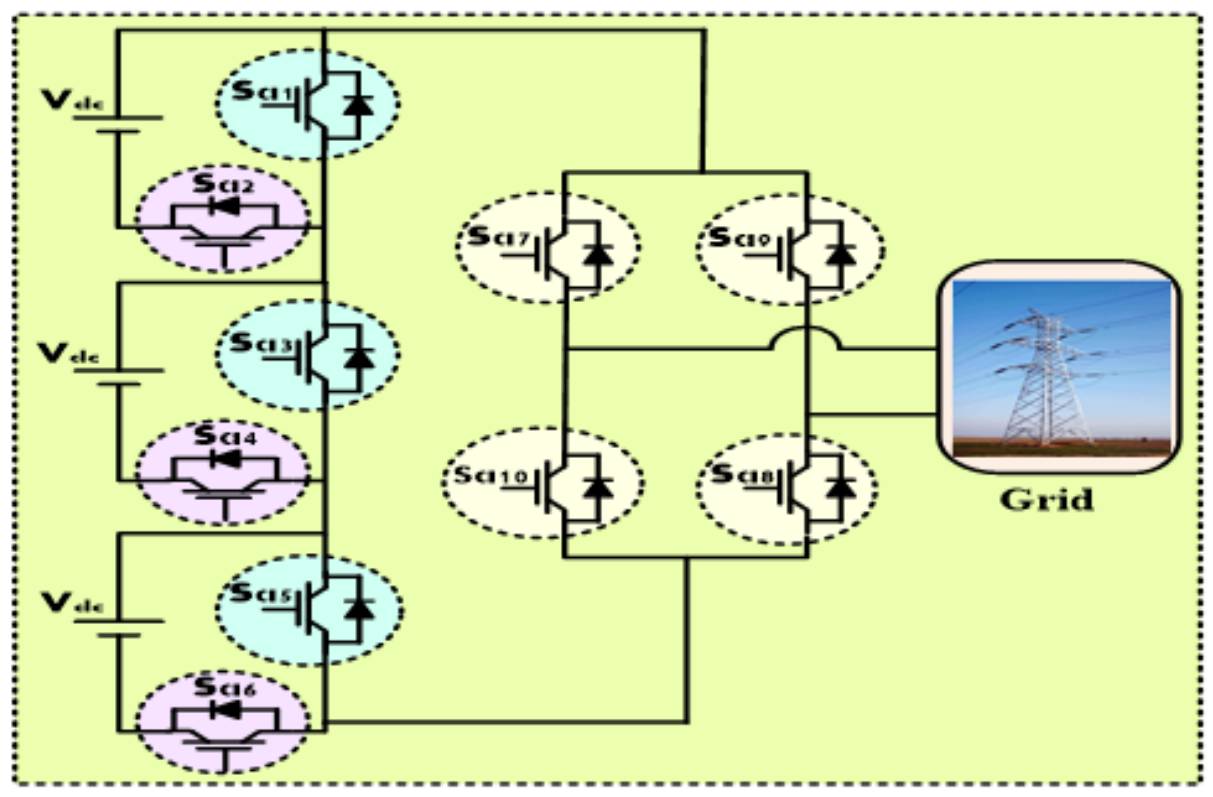

Figure 6. Proposed AMLI inverter topology

\subsection{PWM pattern for switches (Sa1 to Sa6) of proposed MLI using Round Modulation control}

The Round Modulation control (RMC) technique is also known as nearest level control (NLC) technique. In this method, the selection of a nearest voltage level is generated by comparing the desired sinusoidal reference with corresponding inverter output voltage level. The control diagram to generate switching signals for the switches (Sa1 to Sa6) by RMC selection control is as shown in Figure 7. The main advantage of using RMC is that it can be easily extended to any number of levels [13]-[14].

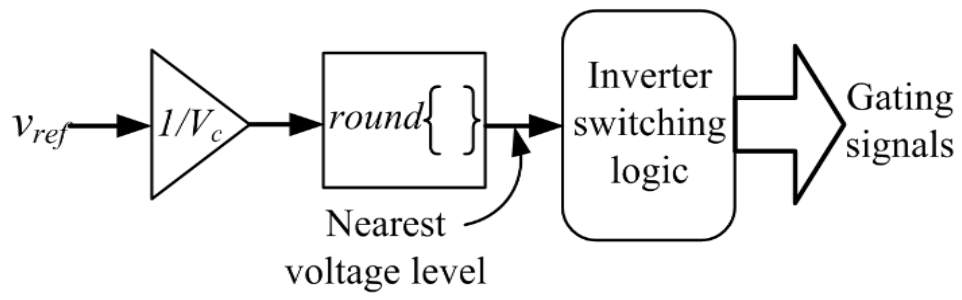

Figure 7. RMC selection control diagram

\subsection{Control of inverting switches in MLI (Sa7 to Sa10)}

The simple control strategy to produce pulses to inverting circuit of MLI was shown in Figure 8. In

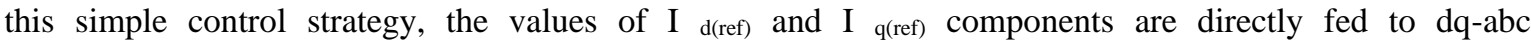
transformation along with the wave shape information from PLL. The obtained reference current signal in 'abc' co-ordinates are again compared with actual components of currents from three phases. The error signal is sent to PWM generator to produce pulses to switches in inverting circuit of MLI. Only three drive circuits 
are employed and using not signals, pulses are sent to remaining switches. Three-phase currents are fed to grid and active power is fed to grid.

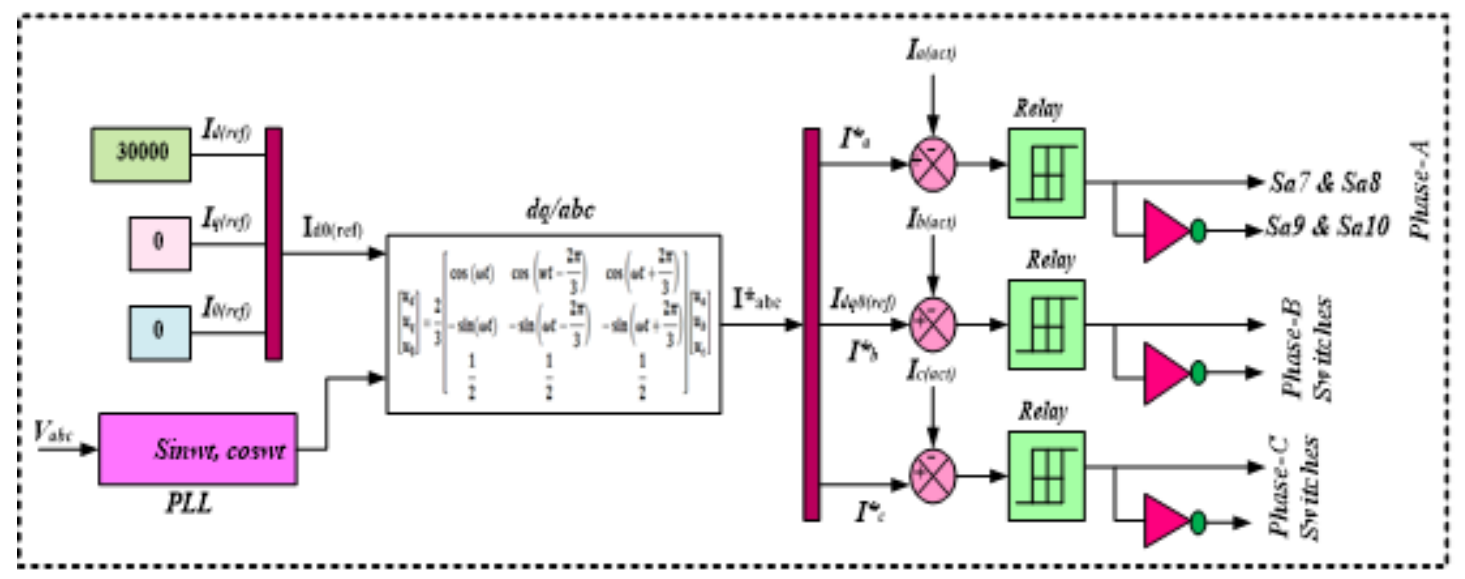

Figure 8. Simple control strategy for inverting circuit of MLI

Complete phenomenon of renewable energy source fed DC-DC converters for high voltage-gain boosting and single input multi-output voltage balancing with proposed 15-level inverter is depicted in Figure 9.

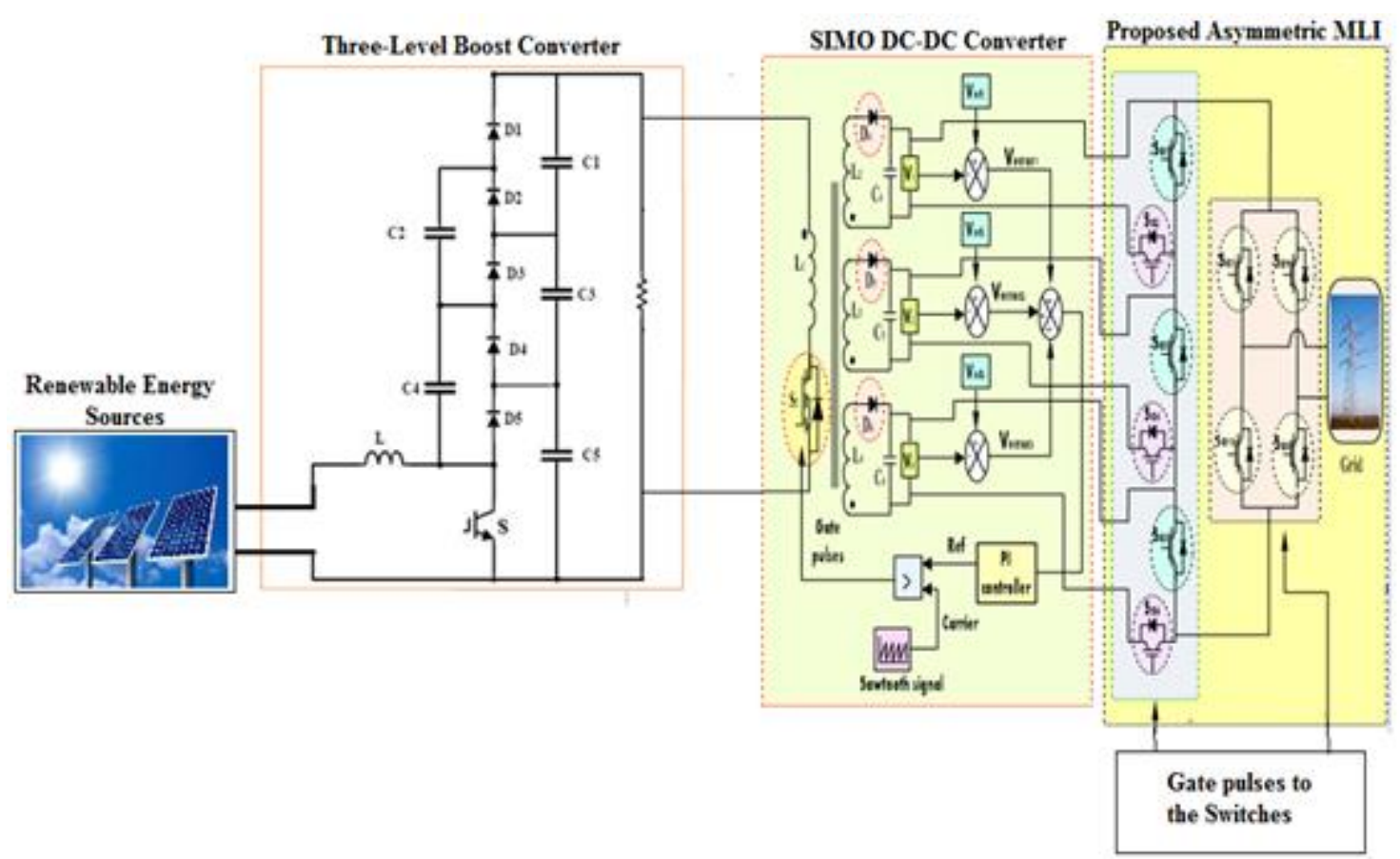

Figure 9. Complete phenomenon of renewable energy source fed DC-DC converters for high voltage-gain boosting and SIMO voltage balancing with proposed AMLI

Grid voltage is taken as reference and fed to phase locked loop to extract the frequency component to generate $I_{d}$ and $I_{q}$ reference components using active and reactive power equations. The reference $I_{d}$ and $I_{q}$ are converted to 'abc' frame with frequency component extracted from grid voltage. This is taken as reference current for grid. Actual current is measured from grid and compared with reference current to generate PWM pulses for H-bridge circuit. Table 1 shows the system parameters used to design simulin models. 
Table 1. System Paprameters

\begin{tabular}{cc}
\hline Parameter & Value \\
\hline Load Resistance & $10 \Omega$ \\
Load Inductance & $10 \mathrm{mH}$ \\
RES Output & $50 \mathrm{~V}$ \\
DC-Link voltage to MLI & $440 \mathrm{~V}$ \\
\hline
\end{tabular}

\section{RESULTS AND ANALYSIS}

Renewable energy source output is shown in Figure 10. Renewable energy source delivers $50 \mathrm{~V}$ output and feeds DC-DC converter. The output of DC-DC MBC converter is shown in Figure 11 . The $50 \mathrm{~V}$ output from RES is boosted to $300 \mathrm{~V}$ by high gain DC-DC converter. The output of SIMO converter to boost the input voltage and also to provide capacitor voltage balance is shown in Figure 12. SIMO converter boosts voltage of $300 \mathrm{~V}$ from MBC converter to $440 \mathrm{~V}$ as shown in Figure 12.

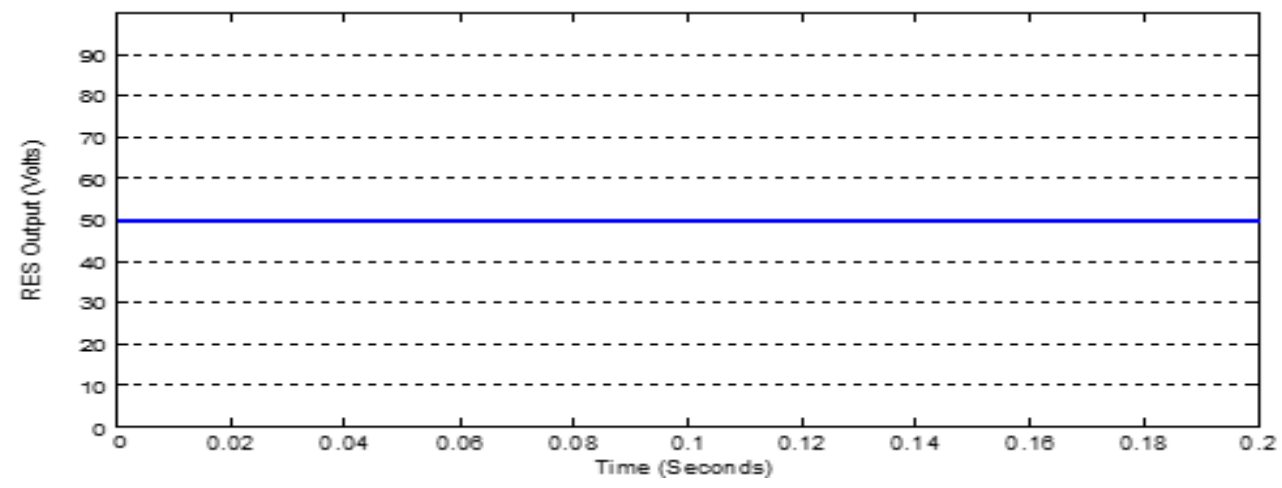

Figure 10. RES output voltage

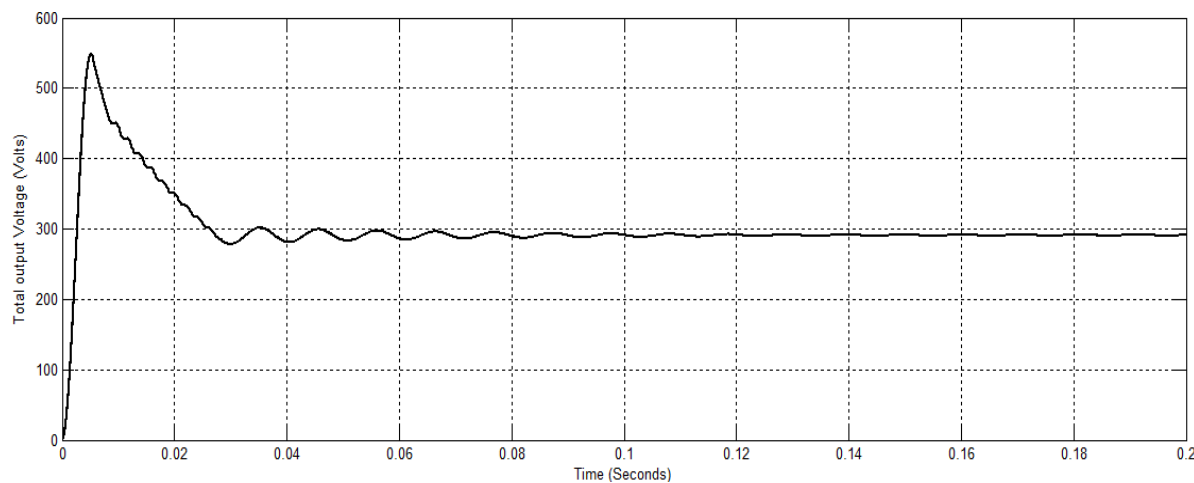

Figure 11. High-gain DC-DC Converter output

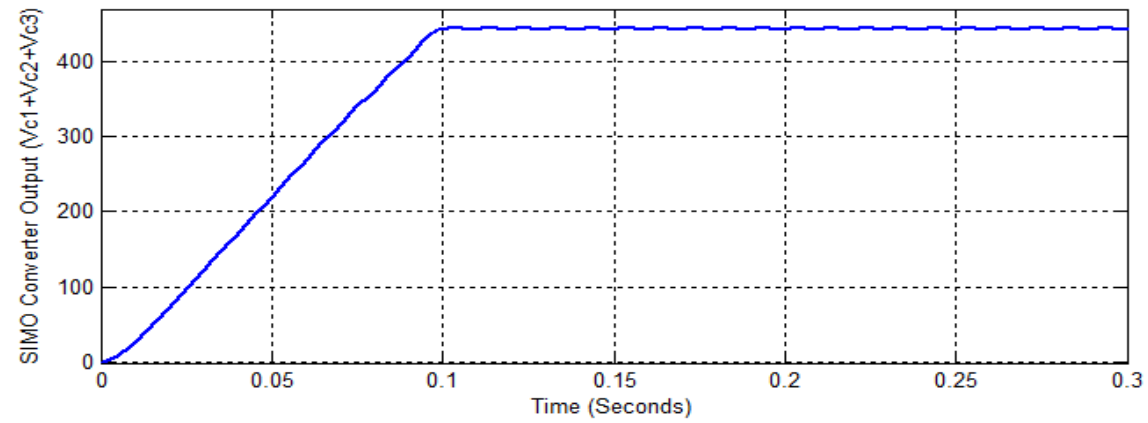

Figure 12. SIMO converter output 
Figure 13 shows the voltage across each capacitor of SIMO converter. Each capacitor maintains the different voltage levels and voltage balance is achieved across all three capacitors of SIMO converter. The three capacitor output voltages are fed to MLI.

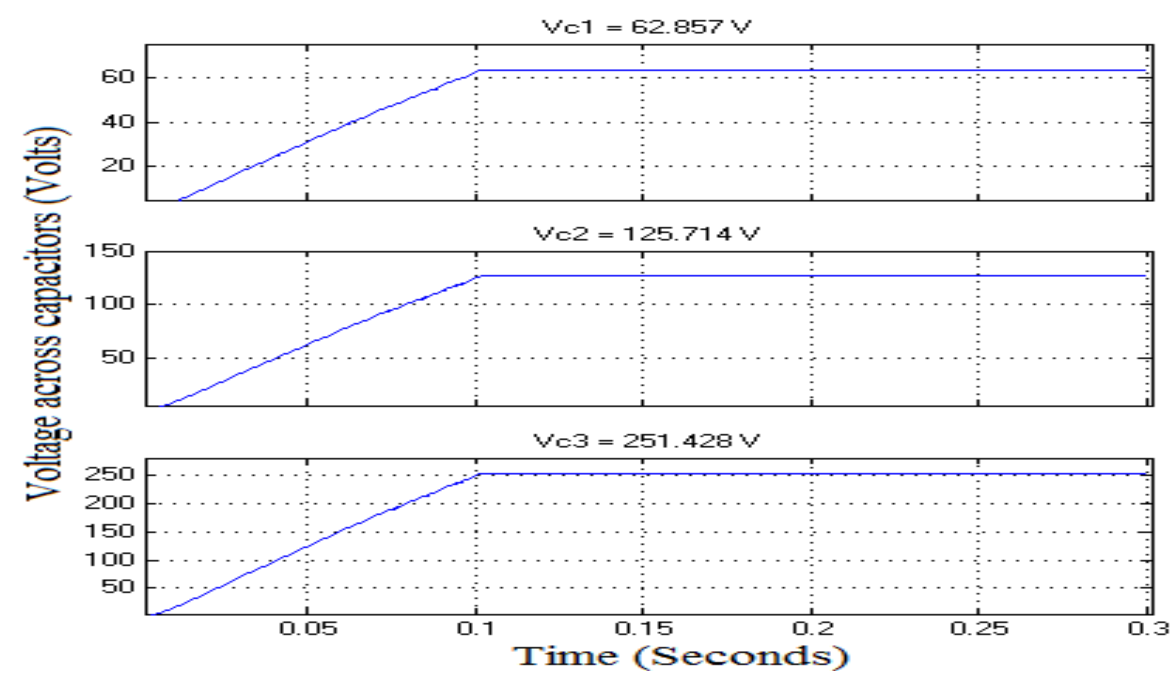

Figure 13. Voltage across each capacitor of SIMO converter

\subsection{Fixed active power fed to grid}

Figure 14 shows the three-phase 15 level output voltages of proposed inverter and Figure 15 shows the phase voltage THD analysis of proposed 15 level inverter. Harmonic distortion of $5.57 \%$ is present in phase voltage of proposed inverter while sending fixed active power component from DG to grid.

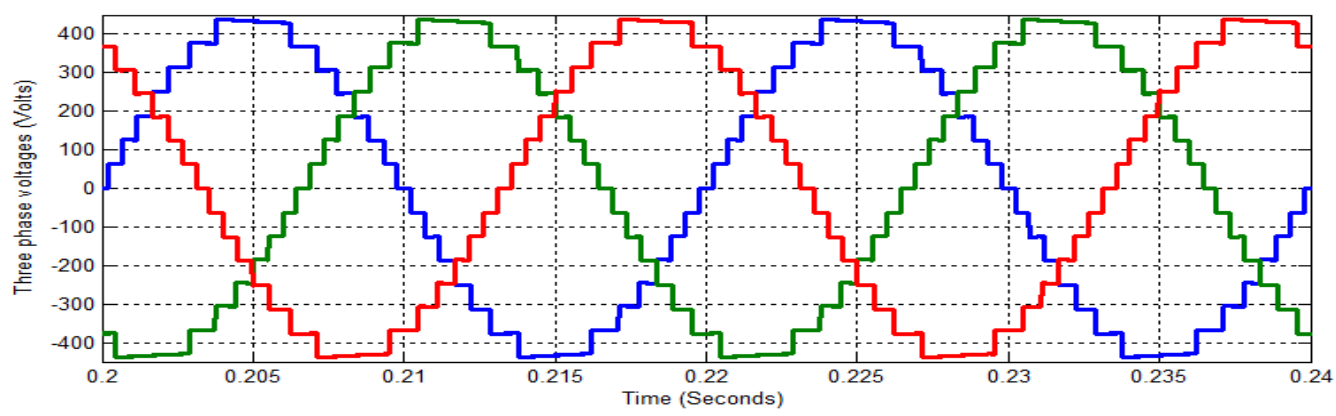

Figure 14. Three Phase voltages of proposed 7-level inverter with fixed load

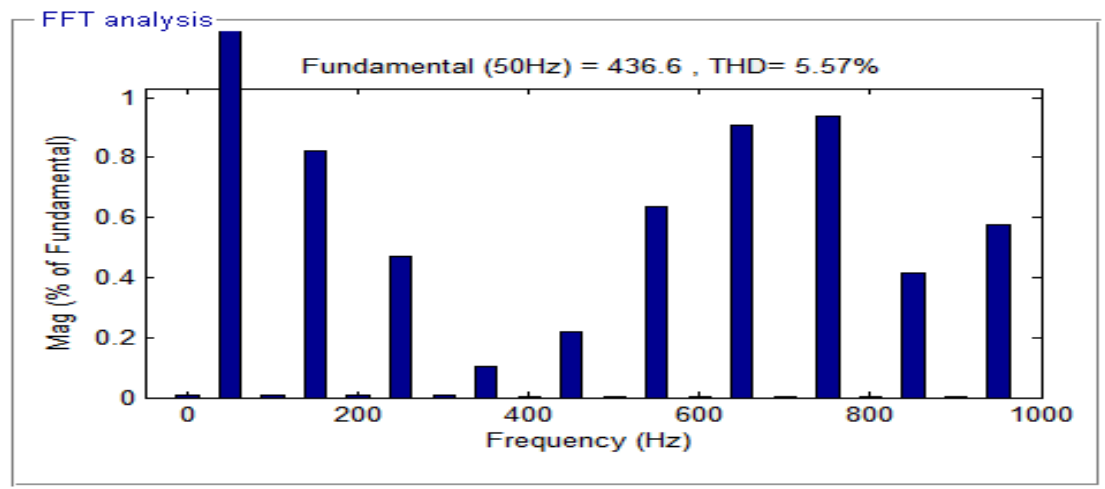

Figure 15. THD analysis of Phase voltage of proposed 15-level inverter 
Figure 16 illustrates the three-phase grid voltages and Figure 17 illustrates the three-phase grid currents while sending fixed active power component from DG to grid. Grid voltage is maintained at $320 \mathrm{~V}$ peak and grid currents are with 60A peak. Since fixed active power component is fed from DG to grid, source current is maintained with constant peak in all the three phases.

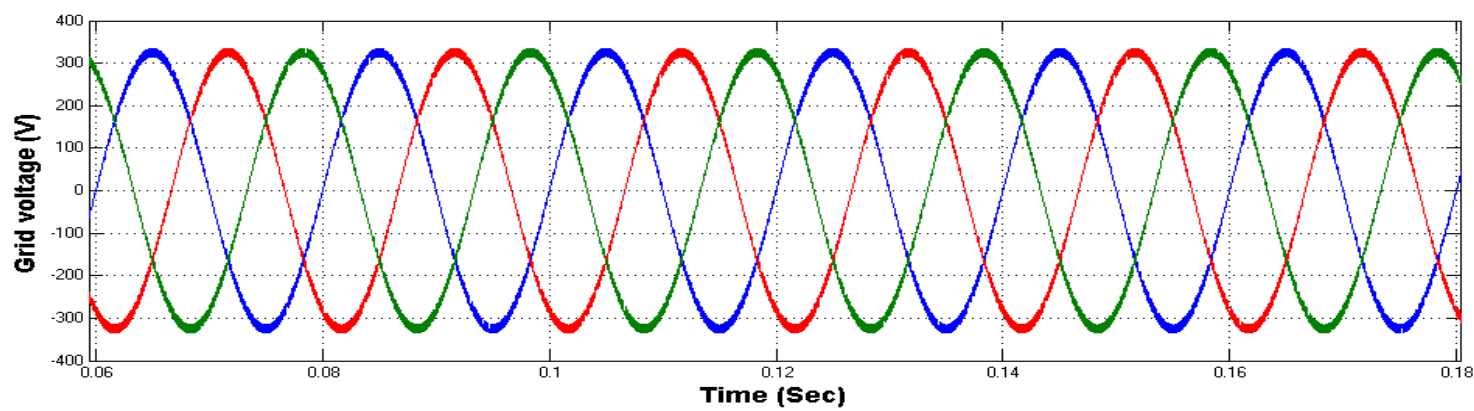

Figure 16. Three phase grid voltages

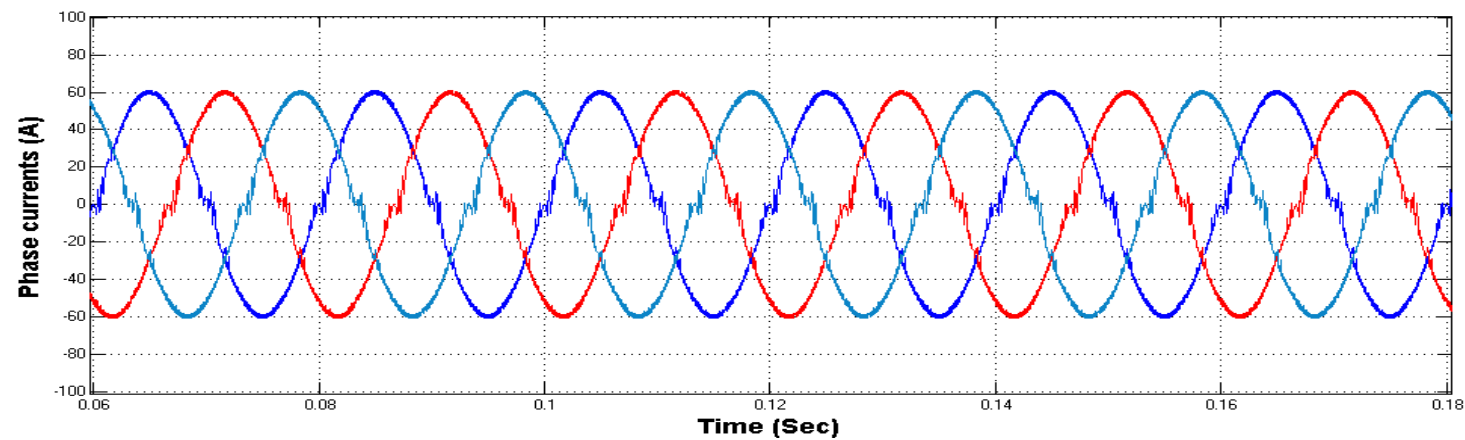

Figure 17. Three phase grid currents

Figure 18 indicates the THD in grid current when feeding fixed active power component from DG to grid. Harmonic distortion of $3.80 \%$ is present which is low and nearly acceptable. Figure 19 indicates power factor angle between grid voltage and current. No phase difference between grid voltage and current is present and hence power factor is maintained near unity.

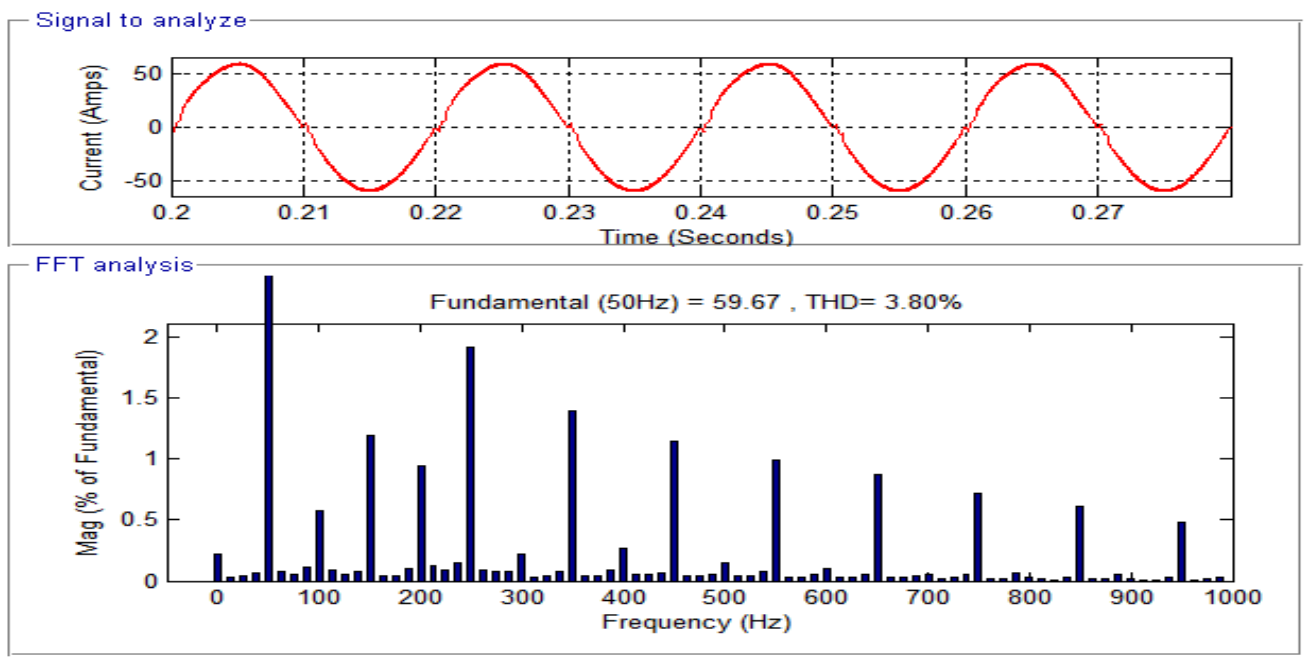

Figure 18. THD in grid current 


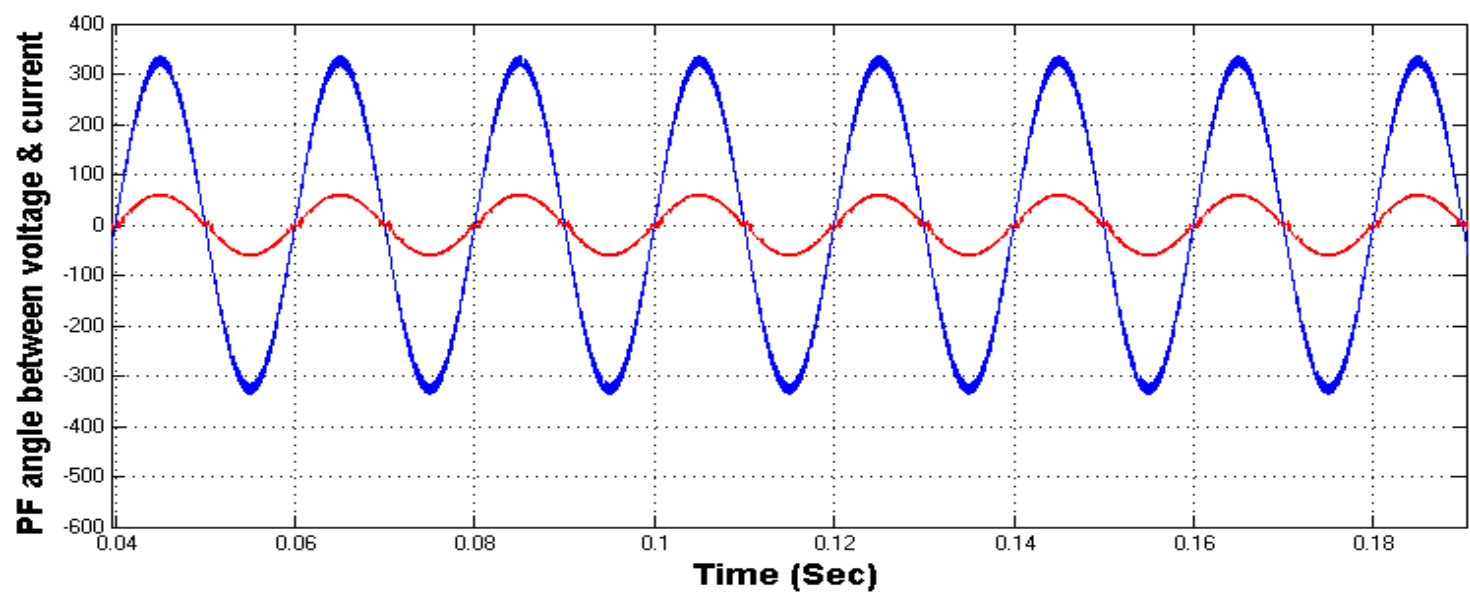

Figure 19. Power factor angle between grid voltage and current

Figure 20 illustrates active power fed to grid from DG. Active power of $30 \mathrm{KW}$ is fed to grid. Figure 21 illustrates reactive power fed to grid from DG. Reactive power is zero and thus no reactive power is fed to grid.

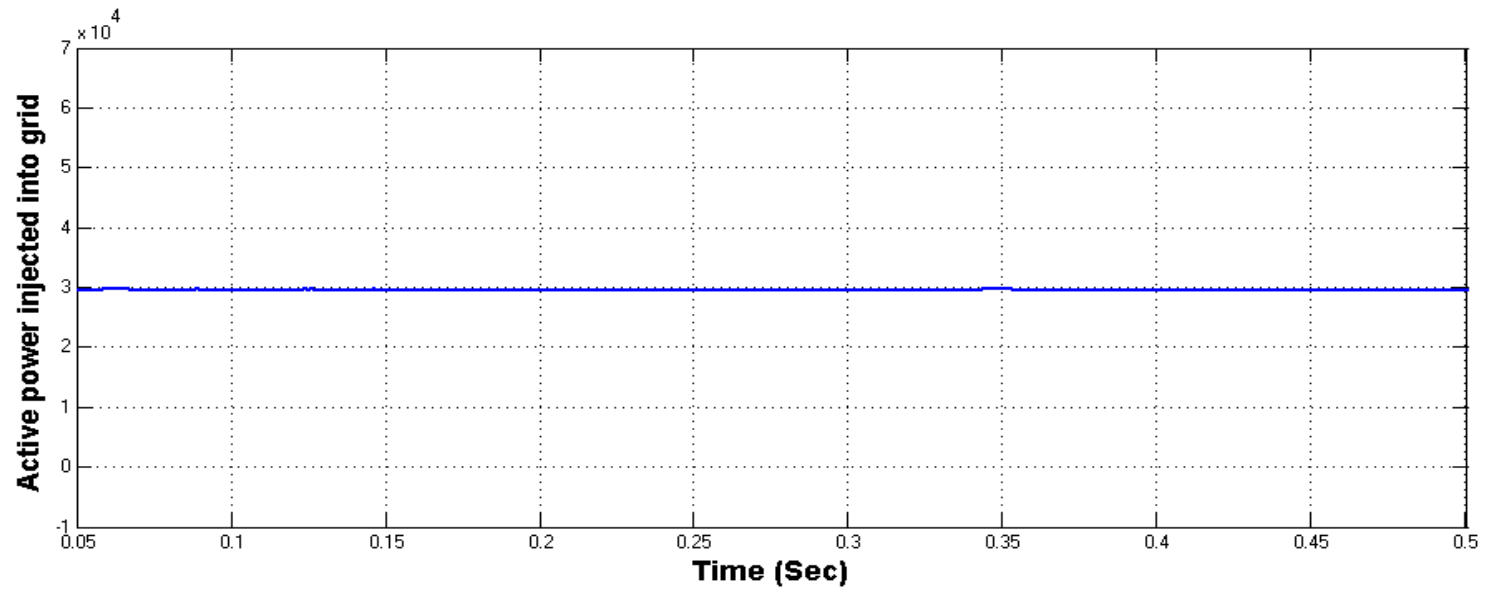

Figure 20. Active power fed to grid

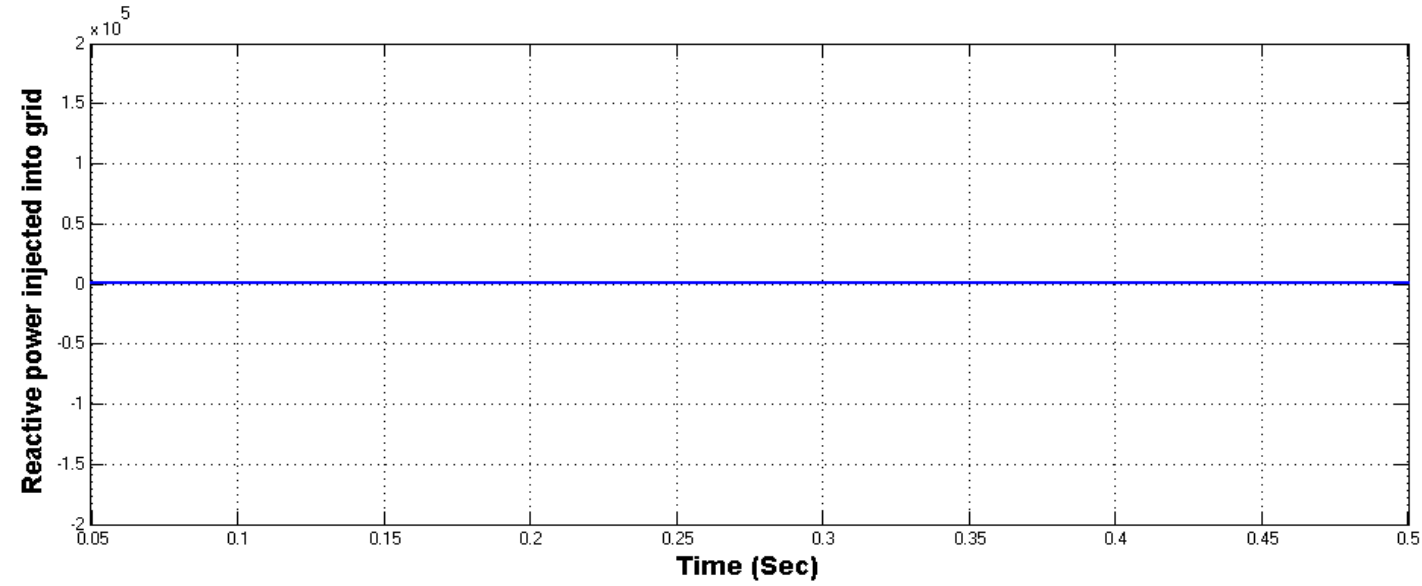

Figure 21. Reactive power fed to grid 


\section{CONCLUSION}

The paper presents grid integration scheme of DG system through a 15 level AMLI structure. Comparing with counterpart well-known and recent MLI structures, the proposed AMLI structure came with reduced number of switching devices, gate driver circuits, DC voltage supplies and less installation area. The DG voltage is stepped up to required level for grid integration through cascaded structure of DC-DC converters. The first of DC-DC converter steps up the DG voltage level and the other DC-DC (SIMO) converter again steps up the DC voltage while producing balanced output voltages to feed three capacitors of MLI structure. PWM pulses trigger the power switches of MLI and simplified control strategy is employed in this paper to control the H-bridge structure of MLI structure. Simplified control strategy is similar to conventional $I_{d}$ and $I_{q}$ theory of active power filters but with some modifications since the theory is applied to grid connected application. DG output voltage, DC-DC converter outputs were shown in result analysis which maintains constant output voltage level. The proposed control theory is verified with fixed power reference. Power factor curves are shown indicating unity power factor maintained in which fixed power reference proving the effectiveness of AMLI structure controlled with proposed simplified control strategy for grid connected applications.

\section{REFERENCES}

[1] H. Geng, et al., "Active islanding detection for inverter-based distributed generation systems with power control interface," IEEE Trans. Energy Convers, vol/issue: 26(4), pp. 1063-1072, 2011.

[2] S. M. M. Tafreshi and E. Mashhour, "Distributed generation modeling for power flow studies and a three-phase unbalanced power flow solution for radial distribution systems considering distributed generation," Elect. Power Syst. Res., vol/issue: 79(4), pp. 680-686, 2009.

[3] F. Li, et al., "Analysis of distributed resources operating in unbalanced distribution circuits," Proc. IEEE Power Eng. Soc. Sum. Meeting, vol. 4 pp. 2315-2319, 2000.

[4] A. D. D. Garcia, et al., "Resilient networked control of distributed energy resources," IEEE J. Sel. Areas Commun., vol/issue: 30(6), pp. 1137-1148, 2012.

[5] J. C. R. Caro, "Voltage balancing in DC/DC multilevel boost converters," 2008 40th North American Power Symposium, 2008.

[6] S. Dasam and B. V. Sankerram, "Voltage Balancing Control Strategy in Converter System for Three-Level Inverters," International Journal of Electrical and Computer Engineering (IJECE), vol/issue: 3(1), pp. 7-14, 2013.

[7] L. S. S. Rao and S. N. Rao, "Three Level Neutral Point Clamped Back to Back Converter," International Journal of Emerging Trends in Electrical and Electronics, vol/issue: 6(1), pp. 45-50, 2013.

[8] DevisreeSasi, et al., "Generalized SVPWM Algorithm for Two Legged Three Phase Multilevel Inverter," International Journal of Power Electronics and Drive System (IJPEDS), vol/issue: 3(3), pp. 279-286, 2013.

[9] A. Camacho, et al., "Flexible voltage support control for three-phase distributed generation inverters under grid fault," IEEE Trans. Ind. Electron., vol/issue: 60(4), pp. 1429-1441, 2013.

[10] E. Pouresmaeil, et al., "A control technique for integration of DG units to the electrical networks," IEEE Trans. Ind. Electron., vol/issue: 60(7), pp. 2881-2893, 2013.

[11] R N. Kumar, "Energy Management system for Hybrid RES with Hybrid Cascaded Multilevel inverter," International Journal of Electrical and Computer Engineering (IJECE), vol/issue: 4(1), pp. 24-30, 2014.

[12] S. N. Rao, et al., "New multilevel inverter topology with reduced number of switches using advanced modulation strategies," Power, Energy and Control (ICPEC), 2013 International Conference on, pp. 693-699, 2013.

[13] V. N. B. Reddy, et al., "Emphasis of Modulated Techniques for Cascaded Multilevel Inverters fed drive using FPGA," Power, Energy and Control (ICPEC), 2013 International Conference on, pp. 686-692, 2013.

[14] S. N. Rao, et al., "Multilevel Inverter Topology for Distributed Generation with High Voltage Gain Cascaded DCDC Converter," Journal of Advanced Research in Dynamical and Control Systems, vol/issue: 9(1), pp. 264-282, 2017.

\section{BIOGRAPHIES OF AUTHORS}

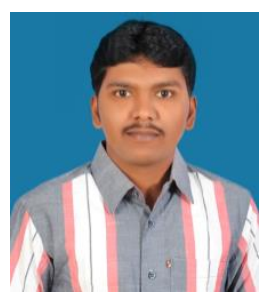

S. Nagaraja Rao was born in Kadapa, India. He received the B.Tech degree in Electrical and Electronics Engineering from the Jawaharlal Nehru Technological University, Hyderabad in 2006; M.Tech (Power Electronics) from the same university in 2008. He is currently an Asst.Professor in the Dept. of Electrical and Electronics Engineering, M.S. Ramaiah University of Applied Sciences, Bangalore. He is currently working towards the Ph.D. degree in Electrical and Electronics Engineering, Jawaharlal Nehru Technological University Kakinada, Kakinada, A.P., INDIA. He has published several papers in National and International Journals and Conferences. His area of interest includes Power electronics and Electric Drives. 


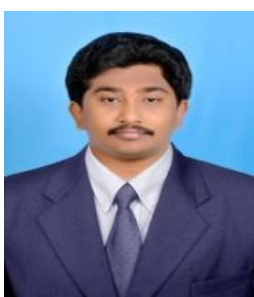

D. V. Ashok Kumar was born in Nandyal, India in 1975. He received the B.E (Electrical and Electronics Engineering) degree from Gulbarga University and the M.Tech (Electrical Power Systems) from J.N.T.U.C.E, Anantapur and Ph.D. in Solar Energy from same University. He is currently a Professor of the Dept. of Electrical and Electronic Engineering and Dean of Administration, R.G.M College of Engineering and Technology, Nandyal, A.P., INDIA. He has published/presented technical research papers in national and international Journals/conferences. His field of interest includes Electrical Machines, Power electronics, Power systems and Solar Energy.

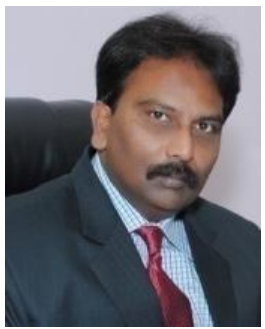

Ch. Sai Babu received the B.E. degree in Electrical and Electronics Engineering, in 1983 from AU College of Engineering Waltair, and the M.Tech. degree in Electrical Machines and Industrial Drives, in 1986 from the Regional Engineering College Warangal, and Ph.D. degree in Reliability Studies of HVDC Converters, in 1996 from Jawaharlal Nehru Technological University Hyderabad, A. P., INDIA. He is currently a Professor of the Dept. of Electrical and Electronic Engineering and Director, Research \& Development, Jawaharlal Nehru Technological University Kakinada, Kakinada, A. P., INDIA. His research interests include Power Electronics, Power Semiconductor controlled electric drives, Resonant Converters, Multilevel Converters, Flexible AC Transmission Systems (FACTS), Power Quality and Solar PV Cell Technologies. He has published over 200 scientific papers in international journals and conferences. 